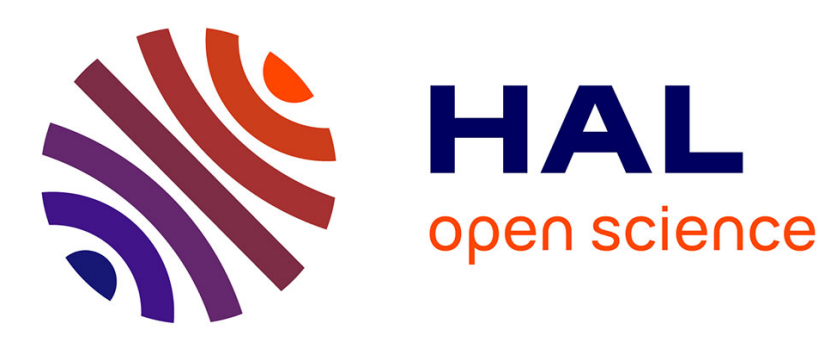

\title{
Listening test methods for perceptual assessment of structural uncertainty
}

Vincent Koehl, Etienne Parizet

\section{To cite this version:}

Vincent Koehl, Etienne Parizet. Listening test methods for perceptual assessment of structural uncertainty. Noise Control Engineering Journal, 2007, 55 (1), pp.55-66. 10.3397/1.2402313 . hal-00414876

\section{HAL Id: hal-00414876 https://hal.science/hal-00414876}

Submitted on 19 Jan 2016

HAL is a multi-disciplinary open access archive for the deposit and dissemination of scientific research documents, whether they are published or not. The documents may come from teaching and research institutions in France or abroad, or from public or private research centers.
L'archive ouverte pluridisciplinaire HAL, est destinée au dépôt et à la diffusion de documents scientifiques de niveau recherche, publiés ou non, émanant des établissements d'enseignement et de recherche français ou étrangers, des laboratoires publics ou privés. 


\title{
Listening test methods for perceptual assessment of structural uncertainty
}

\author{
Vincent Koehl $^{\mathrm{a})}$ and Etienne Parizet ${ }^{\mathrm{b})}$
}

(Received 2006 January 20; revised 2006 June 27; accepted 2006 July 04)

\begin{abstract}
Because of structural uncertainty, an industrial product can exhibit a large variability in its vibratory and acoustical behavior. Many studies have investigated the variation in noise and vibration between structures with nominally identical design. However, the variation of sound perception caused by structural uncertainty has not yet been studied. The aim of this study was to investigate how to assess the perceptual consequences of that physical variability. A mechanical model system, on which structural uncertainty could be simulated, was set up for sound synthesis. The sounds "emitted" by this product were then assessed by a group of listeners performing two different tasks. The first experiment was set up to extract the contribution of uncertainty parameters to the dissimilarity perceived relatively to a reference sound, representing the nominal state of the product. The second experiment made it possible to assess a large set of stimuli and to determine its optimal partition. In all, these tests made it possible to determine which uncertainty parameters did affect sound perception and the perceptual space of the whole set of sounds.

(C) 2007 Institute of Noise Control Engineering.
\end{abstract}

Primary subject classification: 61; Secondary subject classification: 79

\section{INTRODUCTION}

Due to structural uncertainty, "industrially identical" products may exhibit a large variability in their vibratory and acoustical behaviour. Bernhard and Kompella $^{1-3}$ studied that phenomenon on several large sets of cars. The measured frequency response functions due to air-borne and structure-borne excitations on the vehicle exhibited amplitude fluctuations and natural frequencies shifts. A similar study was conducted by Gärdhagen and Plunt ${ }^{4}$ on a simply supported plate. These authors made the same observations when varying the basic features of the plate. The vibratory and acoustical behaviour of an industrial product may then be different from one copy to another. Even though the consequences of structural uncertainty on sound radiation were studied ${ }^{5,6}$ and can be predicted, their perceptual consequences have not been investigated so far. Nevertheless, some papers were devoted to the influence of structural parameters

a) Laboratoire Vibrations Acoustique, Institut National des Sciences Appliquées de Lyon, Bâtiment Saint-Exupéry, 25 bis, avenue Jean Capelle, F-69621 Villeurbanne Cedex, FRANCE; email: vkoehl@1va.insa-lyon.fr

b) Laboratoire Vibrations Acoustique, Institut National des Sciences Appliquées de Lyon Bâtiment Saint-Exupéry, 25 bis, avenue Jean Capelle, F-69621 Villeurbanne Cedex, FRANCE. variations over sound perception. These studies focused on sounds emitted by some basic structures like bars and plates and showed that the level of the sound as well as its pitch, duration and timbre were modified. McAdams et al. ${ }^{7}$ studied the influence of material and geometric modifications on the perception of sound emitted by impacted bars. They showed that a variation of the bar length was perceived through the sound pitch. A variation of the viscoelastic damping of the material modified the decay characteristics and the spectral center of gravity. Faure and Marquis-Favre ${ }^{8}$ studied the influence of structural parameters on the perception of sound radiated by plates. An increase of structural damping diminished the radiated pressure and was perceived as a decrease of loudness. An increase of thickness shifted up the natural frequencies, and what was particularly remarkable in our context is that a small thickness variation (within common tolerance ranges) could be noticed by listeners. It could then be thought that structural uncertainty was aurally noticeable and that this physical variability could also affect the product sound quality.

Nowadays, sound quality is, as many product features, designed to match the customer's expectations. ${ }^{9}$ Sound quality is taken into account in industry and it is useful to know the consequences of structural uncertainty on sound quality. The aim of this work was to develop assessment procedures to evaluate these effects. For that purpose, a basic structure was 


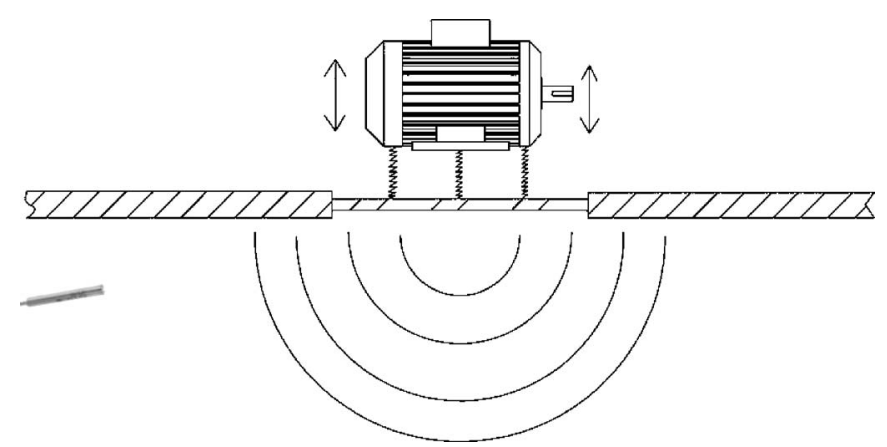

Fig. 1-Academic structure for sound synthesis. The engine is connected to the plate via three mounts. The resulting radiated pressure is used to synthesize sound.

simulated, and the radiation for the plate computed, which allowed to synthesize sounds. Structural variability was introduced in that model, so that sounds representing various uncertainty states could be synthesized. The uncertainty parameters could be finely controlled in the numerical model. Two listening tests were then set up to evaluate the perceptual contribution of these parameters. During the first experiment, listeners had to compare various configurations to the nominal one (without any variability). A fractional factorial design was used to extract the factorial contributions of the uncertainty parameters to sound perception. The second experiment was a categorization task. Listeners had to group similar sounds into equivalence classes. This experiment enabled to assess a large number of stimuli at once and to determine an optimal partition of the stimulus range.

\section{PHYSICAL MODEL FOR SOUND SYNTHESIS}

\subsection{Modeling}

The mechanical model system used to synthesize sounds is shown in Fig. 1. This model was made up of an engine connected to a radiating panel via three elastic mounts. The radiating panel was modeled as a square plate supported on its four edges and mounted in an infinite baffle. The plate was made of steel; the length and thickness were respectively $500 \mathrm{~mm}$ and $1 \mathrm{~mm}$. The geometric and material properties of the plate are summarized in Table 1. The engine exerted a harmonic complex force on the mounts which were considered as pure springs; the nominal stiffness was $100 \mathrm{~N} / \mathrm{mm}$. Table 2 presents the connecting position of each spring on the plate. The springs positions on the plate were not intended to reflect a realistic industrial case but to represent three different connection configurations (middle, corner and intermediate).
Table 1-Geometric and material properties of the plate.

\begin{tabular}{lcc}
\hline \hline Parameter & Symbol & Value \\
\hline Young's modulus & $E$ & $210 \mathrm{~N} / \mathrm{mm}^{2}$ \\
Density & $\rho$ & $7800 \mathrm{~kg} / \mathrm{m}^{3}$ \\
Poisson's ratio & $\nu$ & 0.3 \\
Structural damping & $\eta$ & $3 \%$ \\
Thickness & $h$ & $1 \mathrm{~mm}$ \\
Length & $L$ & $500 \mathrm{~mm}$ \\
\hline \hline
\end{tabular}

\subsection{Radiated Pressure Computation}

All computations were carried out in the frequency domain. The radiation of a simply supported plate mounted in an infinite baffle can be computed using Rayleigh integral. ${ }^{10}$ The three subsystems (engine, mounts and plate) were coupled by the mobility method. The transverse velocity field on the plate was obtained by modal synthesis ${ }^{11}$ between 0 and $2000 \mathrm{~Hz}$, which allowed the computations of the radiated pressure at the listening point. This point is located on the baffle plane at $5 \mathrm{~m}$ from the plate center to be consistent with the far-field hypothesis of Rayleigh integral. Inverse Fourier Transforms of the radiated pressure spectra were used to synthesize the $3 \mathrm{~s}$ long stationary stimuli $\left(f_{S}=44100 \mathrm{~Hz}, 16\right.$-bits resolution).

\subsection{Uncertainty Parameters}

Uncertainty was simulated on each component of the system and was introduced in the analytical computation of the radiated pressure. These variations were within the common tolerance range encountered in industrial processes. ${ }^{12}$ The first two variations concerned the engine excitation spectrum, in the three following variations the stiffness of the springs were changed and in the two last variations the plate properties were modified. An uncertainty affected the global level of the excitation spectrum, which could fluctuate within a $3 \mathrm{~dB}$-wide tolerance range. An axial misalignment amplified $(+1.5 \mathrm{~dB})$ only the even harmonics of this spectrum. The structural damping ${ }^{13}$ could vary between $2 \%$ and $4 \%$ for the steel plate. Its nominal thickness was $1 \mathrm{~mm}$, the tolerance range for this type

Table 2-Connecting positions of the three mounts on the plate. The $x$ - and $y$-distances to the plate corner are expressed in $\mathrm{mm}$.

\begin{tabular}{lcc}
\hline \hline Mount no. & $x$-position & $y$-position \\
\hline 1 & 125 & 175 \\
2 & 100 & 100 \\
3 & 250 & 250 \\
\hline \hline
\end{tabular}


Table 3-Uncertainty parameters and corresponding nominal values and tolerance ranges. $F$ represents the whole force spectrum, while $F_{2 n}$ represents only its even harmonics.

\begin{tabular}{lcc}
\hline \hline Uncertainty parameter & Nominal value & Tolerance range \\
\hline Axial misalignment & $F_{2 n}$ & {$\left[F_{2 n} ; F_{2 n}+1.5 \mathrm{~dB}\right]$} \\
Global level & $F$ & {$[F-1.5 \mathrm{~dB} ; F+1.5 \mathrm{~dB}]$} \\
Stiffness 1 & $100 \mathrm{~N} / \mathrm{mm}$ & {$[80 \mathrm{~N} / \mathrm{mm} ; 120 \mathrm{~N} / \mathrm{mm}]$} \\
Stiffness 2 & $100 \mathrm{~N} / \mathrm{mm}$ & {$[80 \mathrm{~N} / \mathrm{mm} ; 120 \mathrm{~N} / \mathrm{mm}]$} \\
Stiffness 3 & $100 \mathrm{~N} / \mathrm{mm}$ & {$[80 \mathrm{~N} / \mathrm{mm} ; 120 \mathrm{~N} / \mathrm{mm}]$} \\
Plate thickness & $1 \mathrm{~mm}$ & {$[0.9675 \mathrm{~mm} ; 1.0325 \mathrm{~mm}]$} \\
Structural damping & $3 \%$ & {$[2 \% ; 4 \%]$} \\
\hline \hline
\end{tabular}

of plate being $0.065 \mathrm{~mm}$, according to NF A 46-402 standard. ${ }^{14}$ For each of the three springs, a variation of $\pm 20 \%$ around the nominal stiffness was simulated. Such a deviation can commonly be observed in commercial products. The reference sound was obtained when all uncertainty parameters were left at their nominal values. Uncertainty parameters, nominal values and tolerance ranges are summarized in Table 3 . Two listening tests were set up to investigate the influence of this structural uncertainty on sound perception.

\section{PERCEPTUAL ASSESSMENT OF SYNTHESIZED SOUNDS}

\subsection{Subjects}

The intra- and inter-individual variability related to the dissimilarity evaluation test was estimated in a previous paper ${ }^{15}$ and proved to be very low. Hence, the number of 20 listeners was considered as sufficient to perform the first experiment (dissimilarity evaluation). Students (6 females and 14 males) from the laboratory were selected, their ages ranged from 22 to 25 years. All reported having normal hearing. The same listeners participated to the second experiment (categorization). Both tests were performed once by each participant.

\subsection{Apparatus}

Experiments took place in the laboratory. Listeners were seated in an isolated listening room. Sounds were reproduced for diotic hearing with a PC equipped with an Echo Digital Audio GINA24 soundcard via a set of Sennheiser HD600 headphones. Sounds were stationary and their levels (measured with a Bruël \& Kjær type 4100 artificial head) ranged from 74.7 to $84.1 \mathrm{dBA}$. Subjects had no information about the source of the sounds.

\subsection{Dissimilarity Evaluation Test}

This perceptual assessment method was used to investigate the influence of the variation of the mechanical parameters on the dissimilarity perceived between each stimulus and a reference one. Uncertainty configurations were synthesized so that the factorial contributions of the mechanical parameters could be extracted from the perceptual assessments.

\subsubsection{Stimuli}

To limit the number of stimuli to be assessed, a fractional factorial design was used. The usefulness of this technique for perceptual experiments was shown in a previous study ${ }^{15}$ In this systematic approach, all factors (i.e. uncertainty parameters) were varied simultaneously according to a special experiment layout. ${ }^{16}$ Assuming that the factor effects were independent, each measurement should then reveal relevant information about the design factors. Except for the axial misalignment and as specified in Table 4, three observation levels were selected for each factor: the lower limit of the tolerance range, the nominal value and the upper limit of the tolerance range. Since the axial misalignment (factor $A$ ) could only amplify the even harmonics of the excitation spectrum, two observation levels were attributed to it: the nominal value and the upper limit of the tolerance range. The selected experimental design, referenced as $L_{18}$ by Taguchi and Konishi,${ }^{17}$ is described in Table 5. This table summarizes the factor combinations for all synthesized sounds. The orthogonal array enabled the exploration of the effects of the 7 design factors on the measured response (perceived dissimilarity) at each of their levels with only 18 configurations. It should be pointed out that listeners' answers had to be measured on a continuous scale for that purpose. Sounds were synthesized according to this experimental design and presented to listeners for perceptual assessment. This orthogonal array also enabled the testing of the interaction between factors $A$ ( 2 levels) and $B$ (3 levels), referred as $A B$ in the following in this paper. In order to validate the hypothesis of factor independence, six complementary configurations were added to the 
Table 4-Design factors and their levels in the experiment.

\begin{tabular}{lcccc}
\hline \hline \multirow{3}{*}{ Factor } & $\begin{array}{c}\text { Corresponding mechanical } \\
\text { uncertainty }\end{array}$ & & \multicolumn{3}{c}{ Level } \\
\cline { 3 - 5 } & & 0 & 2 & 3 \\
\hline A & Axial misalignment & $-1.5 \mathrm{~dB}$ & 0 & $+1.5 \mathrm{~dB}$ \\
$B$ & Force spectrum level & $80 \mathrm{~N} / \mathrm{mm}$ & $100 \mathrm{~N} / \mathrm{mm}$ & $120 \mathrm{~N} / \mathrm{mm}$ \\
$C$ & First engine mount & $80 \mathrm{~N} / \mathrm{mm}$ & $100 \mathrm{~N} / \mathrm{mm}$ & $120 \mathrm{~N} / \mathrm{mm}$ \\
$D$ & Second engine mount & $80 \mathrm{~N} / \mathrm{mm}$ & $100 \mathrm{~N} / \mathrm{mm}$ & $120 \mathrm{~N} / \mathrm{mm}$ \\
$E$ & Third engine mount & $0.9675 \mathrm{~mm}$ & $1 \mathrm{~mm}$ & $1.0325 \mathrm{~mm}$ \\
$F$ & Plate thickness & $2 \%$ & $3 \%$ & $4 \%$ \\
$G$ & Structural damping & &
\end{tabular}

orthogonal array. The resulting stimuli (sounds 19 to 24 in Table 5) were included in the perceptual assessment but were not used to compute factor effects and contri-

Table 5-Factor assignment for the synthesis configurations, sounds 1 to 18 according to the $L_{18}$ experimental design, sounds 19 to 24 for validation. Sound 25 is the reference.

\begin{tabular}{|c|c|c|c|c|c|c|c|c|}
\hline \multirow[t]{2}{*}{$\begin{array}{l}\text { Sound } \\
\text { no. }\end{array}$} & \multicolumn{7}{|c|}{ Controlled factors } & \multirow{2}{*}{$\begin{array}{c}\text { Interaction } \\
\mathrm{AB}\end{array}$} \\
\hline & $A$ & $B$ & $C$ & $D$ & $E$ & $F$ & $G$ & \\
\hline 1 & 1 & 1 & 1 & 1 & 1 & 1 & 1 & 1 \\
\hline 2 & 1 & 1 & 2 & 2 & 2 & 2 & 2 & 1 \\
\hline 3 & 1 & 1 & 3 & 3 & 3 & 3 & 3 & 1 \\
\hline 4 & 1 & 2 & 1 & 1 & 2 & 2 & 3 & 2 \\
\hline 5 & 1 & 2 & 2 & 2 & 3 & 3 & 1 & 2 \\
\hline 6 & 1 & 2 & 3 & 3 & 1 & 1 & 2 & 2 \\
\hline 7 & 1 & 3 & 1 & 2 & 1 & 3 & 2 & 3 \\
\hline 8 & 1 & 3 & 2 & 3 & 2 & 1 & 3 & 3 \\
\hline 9 & 1 & 3 & 3 & 1 & 3 & 2 & 1 & 3 \\
\hline 10 & 2 & 1 & 1 & 3 & 3 & 2 & 2 & 4 \\
\hline 11 & 2 & 1 & 2 & 1 & 1 & 3 & 3 & 4 \\
\hline 12 & 2 & 1 & 3 & 2 & 2 & 1 & 1 & 4 \\
\hline 13 & 2 & 2 & 1 & 2 & 3 & 1 & 3 & 5 \\
\hline 14 & 2 & 2 & 2 & 3 & 1 & 2 & 1 & 5 \\
\hline 15 & 2 & 2 & 3 & 1 & 2 & 3 & 2 & 5 \\
\hline 16 & 2 & 3 & 1 & 3 & 2 & 3 & 1 & 6 \\
\hline 17 & 2 & 3 & 2 & 1 & 3 & 1 & 2 & 6 \\
\hline 18 & 2 & 3 & 3 & 2 & 1 & 2 & 3 & 6 \\
\hline 19 & 1 & 1 & 1 & 2 & 3 & 1 & 2 & 1 \\
\hline 20 & 1 & 2 & 3 & 1 & 2 & 3 & 1 & 2 \\
\hline 21 & 1 & 3 & 2 & 3 & 1 & 2 & 3 & 3 \\
\hline 22 & 2 & 1 & 3 & 2 & 1 & 3 & 2 & 4 \\
\hline 23 & 2 & 2 & 1 & 3 & 2 & 1 & 3 & 5 \\
\hline 24 & 2 & 3 & 2 & 1 & 3 & 2 & 1 & 6 \\
\hline 25 & 1 & 2 & 2 & 2 & 2 & 2 & 2 & 2 \\
\hline
\end{tabular}

butions. For these configurations, each factor level was assigned twice so that each interaction level was represented once.

\subsubsection{Procedure}

During this experiment, listeners had to evaluate the dissimilarity of 24 stimuli to one reference sound, with all mechanical parameters at their nominal value. This stimulus represented thus the ideal state of the system. As shown in Fig. 2, all the 25 sounds (the reference sound, the eighteen sounds from the experimental design and the six validation ones) were displayed on the test window at the same time. Sounds were presented in random order, the number attributed to each sound in the test window having no link with its number in the experiment table. Stimuli were rated by listeners along an axis indicating the "increasing dissimilarity" ("différence croissante") and starting from "identical to reference sound" ("identique au son de référence", dissimilarity mark 0 ). The rating scale was continuous and the maximal dissimilarity mark was attributed the value of 1 . Before the beginning of the test, all stimuli were played once as instructions for listeners were displayed on the screen. Subjects could listen to each stimulus as many times as they wanted to compare it to the reference sound as well as to any other one. To make the test easier and to allow more refined ratings, participants could reorganize sounds from the closest to the furthest distance to the reference. This test procedure was adapted from an assessment method for sensory pleasantness evaluation. ${ }^{18}$ The test duration varied from 14 to $28 \mathrm{~min}$ and was typically $16 \mathrm{~min}$.

\subsubsection{Results}

The dissimilarity marks were averaged over all subjects to obtain the dissimilarity score for each stimulus. In Fig. 3 are shown the dissimilarity scores in their $95 \%$ confidence interval, for the 24 assessed 


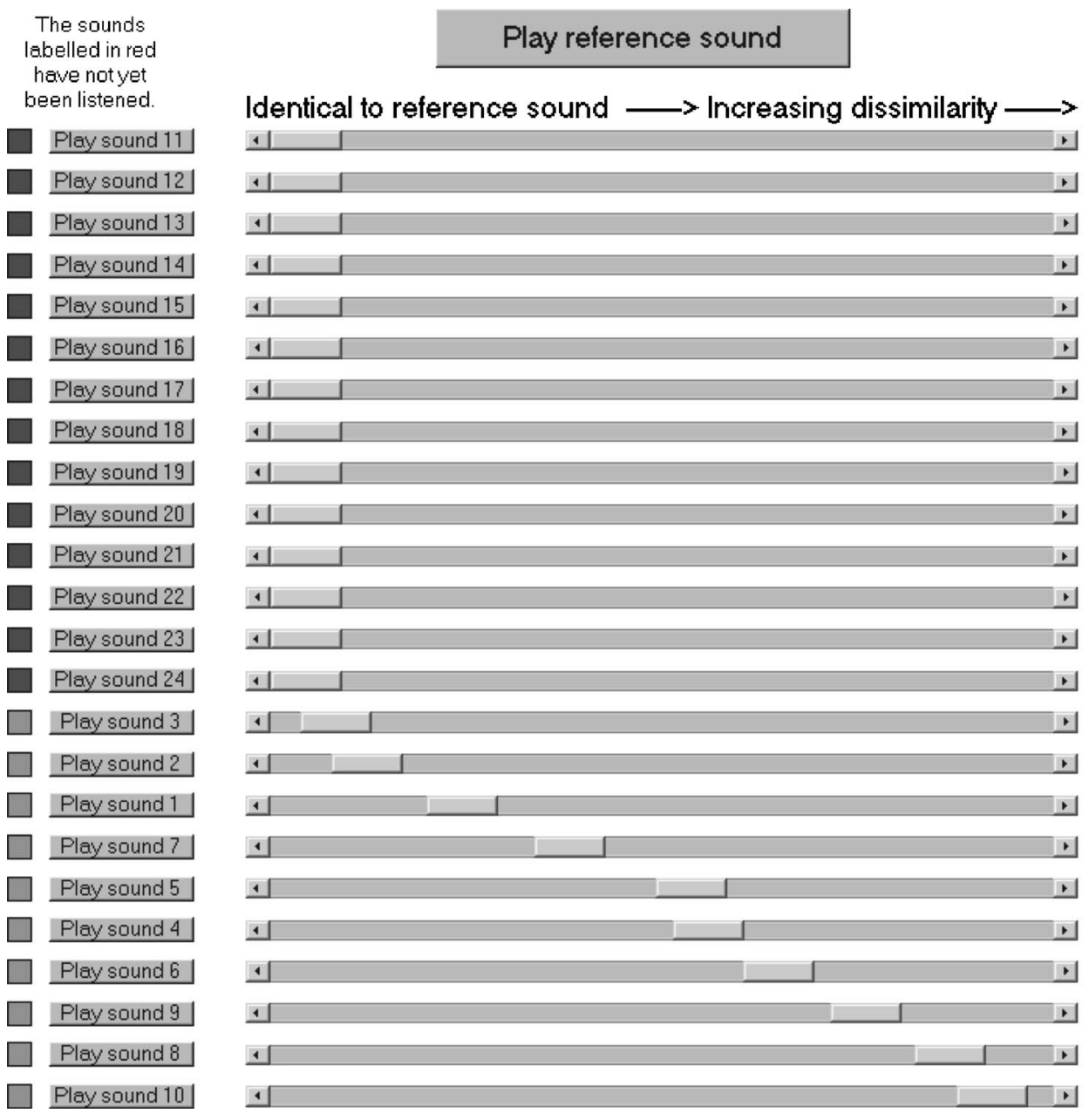

Click here to reorganize increasing dissimilarity

\section{Reorganize sounds}

Fig. 2-Screen shot of the dissimilarity evaluation window (running). Each button on the left enables a sound to be played, its evaluation cursor being placed beside. The top button enables the reference sound to be played. A button on the left allows a reordering of sounds according to increasing dissimilarity ratings. In the present case, the subject has already listened and rearranged some sounds.

sounds. The lower the dissimilarity score was, the more the sound was perceived as close to the reference. At each observation level, the factor effects could be deduced from the measured dissimilarity scores $\left(S_{m}\right)$ of sounds 1 to 18 . As an example, the effect of factor $B$ at level $1\left(E_{B 1}\right)$ was obtained using the measured dissimilarity scores of sounds in this synthesis configuration, according to Table 5:

$$
E_{B 1}=\frac{S_{m}(1)+S_{m}(2)+S_{m}(3)+S_{m}(10)+S_{m}(11)+S_{m}(12)}{6}-\bar{M}
$$

where $S_{m}(i)$ is the measured score of sound $i$ and $\bar{M}$ is the overall mean of measured dissimilarity judgments:

$$
\bar{M}=\frac{\sum_{i=1}^{18} S_{m}(i)}{18}=0.57
$$

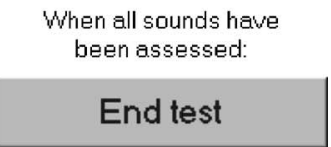




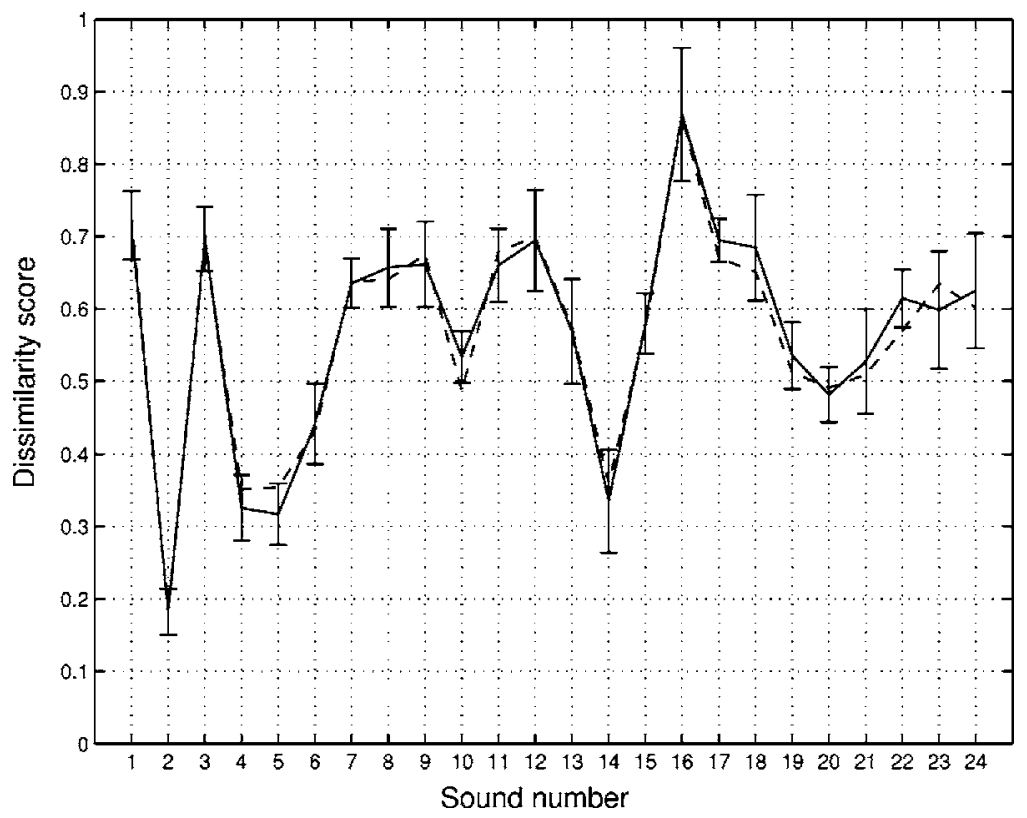

Fig. 3-Measured dissimilarity scores (solid line) in their 95\% confidence intervals and computed ones (dashed line).

$$
\begin{aligned}
S_{c}(i)= & \bar{M}+E_{A(i)}+E_{B(i)}+E_{C(i)}+E_{D(i)}+E_{E(i)}+E_{F(i)} \\
& +E_{G(i)}+E_{A B(i)}
\end{aligned}
$$

where $S_{c}(i)$ is the computed dissimilarity score for sound $i . E_{A(i)}, E_{B(i)}, E_{C(i)} \ldots E_{A B(i)}$ are the factors effects on measurement $i$. The additive dissimilarity model described by Eqn. (3) made possible the computation of the dissimilarity scores for each measurement (dashed line in Fig. 3). For that purpose, the factor effects shown in Table 6 were added to $\bar{M}$ [Eqn. (2)]. Additional measurements (sounds 19 to 24), for which measured and computed dissimilarity appeared very close to one another, allowed validation of that additive model. It could thus be established that no other effect or interaction played any significant part in the measured response.
An analysis of variance was then conducted on the dissimilarity scores to extract the influence of each design parameter (i.e. structural uncertainty) on the perceived similarity. As shown in Table 7, the most influential factor (39.98\% of the explained variance) was the global level of the excitation spectrum. This factor directly affected the sound level. In comparison, the axial misalignment contribution, which only concerned the even harmonics of the excitation spectrum, was lower $(9.66 \%)$. It could be noticed that the influence of a mount stiffness depended on its position on the plate. The stiffness variation of the third spring, connected at the plate center $(x=250 \mathrm{~mm}$; $y=250 \mathrm{~mm})$, had almost no influence $(0.53 \%)$ on the dissimilarity judgments. The stiffness variation contribution was related to the number of plate modes

Table 6-Factor effects on the measured response for the dissimilarity evaluation experiment.

\begin{tabular}{lcccccc}
\hline \hline \multirow{2}{*}{ Factor } & \multicolumn{5}{c}{ Level } \\
\cline { 2 - 7 } & 1 & 2 & 3 & 4 & 5 & 6 \\
\hline A (Misalignment) & -0.055 & +0.055 & & & & \\
B (Spectrum level) & +0.011 & -0.142 & +0.131 & & & \\
C (Mount 1) & +0.038 & -0.096 & +0.057 & & & \\
D (Mount 2) & +0.037 & -0.056 & +0.019 & & & \\
E (Mount 3) & +0.009 & -0.018 & +0.009 & & & \\
F (Thickness) & +0.059 & -0.116 & +0.057 & & & \\
G (Damping) & +0.029 & -0.058 & +0.029 & & & \\
AB (Interaction) & +0.01 & -0.01 & +0.01 & -0.01 & +0.01 & -0.01 \\
\hline \hline
\end{tabular}


Table 7-ANOVA results for dissimilarity ratings.

\begin{tabular}{|c|c|c|c|c|c|}
\hline Factor & DOF & $\mathrm{SS}$ & MS & $\mathrm{F}$ & Contribution \\
\hline A (Misalignment) & 1 & 1.08 & 1.08 & $1335.64^{b}$ & $9.66 \%$ \\
\hline B (Spectrum level) & 2 & 4.48 & 2.24 & $2761.88^{\mathrm{b}}$ & $39.98 \%$ \\
\hline $\mathrm{C}($ Mount 1$)$ & 2 & 1.66 & 0.83 & $1025.52^{b}$ & $14.84 \%$ \\
\hline D (Mount 2) & 2 & 0.58 & 0.29 & $357.54^{\mathrm{b}}$ & $5.16 \%$ \\
\hline E (Mount 3) & 2 & 0.06 & 0.03 & $37.33^{\mathrm{a}}$ & $0.53 \%$ \\
\hline F (Thickness) & 2 & 2.42 & 1.21 & $1490.30^{\mathrm{b}}$ & $21.57 \%$ \\
\hline G (Damping) & 2 & 0.61 & 0.31 & $377.90^{b}$ & $5.46 \%$ \\
\hline AB (Interaction) & 2 & 0.02 & 0.01 & $15.12^{\mathrm{a}}$ & $0.20 \%$ \\
\hline Residue & 344 & 0.28 & 0.00 & & $2.60 \%$ \\
\hline Total & 359 & 11.19 & & & \\
\hline
\end{tabular}

excited by the connecting point. The second connection, located near the corner $(x=100 \mathrm{~mm} ; y=100 \mathrm{~mm})$, should be the one exciting the largest number of modes, but obviously at lower modal amplitudes than the first position $(x=125 \mathrm{~mm} ; y=175 \mathrm{~mm})$. The contribution of the stiffness variation was $14.84 \%$ for the first spring, and $5.16 \%$ for the second one. Even though its tolerance range was narrow, the variation of thickness was clearly perceived by listeners and was then the second most influential factor $(21.57 \%)$. Faure and Marquis-Favre ${ }^{8}$ had already shown that small thickness variations of plates were perceived through the radiated sound. These authors also found that a small damping variation $\left(\eta \in\left[10^{-3} ; 10^{-2}\right]\right.$ ) was clearly perceived. In our study, this parameter was not very influential $(5.46 \%)$ which might be due to a smaller relative variation range $\left(\eta \in\left[2.10^{-2} ; 4.10^{-2}\right]\right)$. The interaction and the residue had very weak contributions to the measured response, respectively $0.20 \%$ and $2.60 \%$, which confirmed that no other factor or interaction had any significant effect on the measured response.

\subsection{Categorization Test}

This perceptual experiment was conducted to determine distances between all stimulus pairs during a task enabling the testing of more sounds than a classical paired comparison test. Each listener had to establish a partition of the stimulus set. The optimal partition could be deduced from the individual ones, the interindividual differences within the individual partitions led to a distance matrix.

\subsubsection{Stimuli}

The task of the categorization experiment consisted in gathering sounds into equivalence classes. No distance, either between sounds or between groups, was considered, so that the answers were not continuous. This test procedure could not be combined with the fractional factorial design technique. To compensate for this drawback, the number of sounds was increased: 13 additional sounds were added to the 25 previous ones. In the same way as Table 5, Table 8 summarizes the factor combinations for these additional sounds. Sound 26 was identical to sound 25 , radiated by the nominal state of the device. Sounds 27 to 30 enabled the testing of the extreme configurations of the experimental field. Sounds 31 to 38 implied only

Table 8-Factor assignment for the additional synthesis configurations to the categorization test.

\begin{tabular}{|c|c|c|c|c|c|c|c|c|}
\hline \multirow[t]{2}{*}{$\begin{array}{l}\text { Sound } \\
\text { no. }\end{array}$} & \multicolumn{4}{|c|}{ Controlled factors } & \multicolumn{4}{|c|}{ Interaction } \\
\hline & $A$ & $B$ & $C$ & $D$ & $E$ & $F$ & $G$ & $A B$ \\
\hline 26 & 1 & 2 & 2 & 2 & 2 & 2 & 2 & 2 \\
\hline 27 & 1 & 3 & 3 & 3 & 3 & 3 & 3 & 3 \\
\hline 28 & 2 & 1 & 1 & 1 & 1 & 1 & 1 & 4 \\
\hline 29 & 2 & 2 & 2 & 2 & 2 & 2 & 2 & 5 \\
\hline 30 & 2 & 3 & 3 & 3 & 3 & 3 & 3 & 6 \\
\hline 31 & 1 & 1 & 1 & 1 & 1 & 2 & 1 & 1 \\
\hline 32 & 1 & 1 & 1 & 1 & 1 & 2 & 3 & 1 \\
\hline 33 & 1 & 1 & 3 & 3 & 3 & 2 & 1 & 1 \\
\hline 34 & 1 & 1 & 3 & 3 & 3 & 2 & 3 & 1 \\
\hline 35 & 1 & 3 & 1 & 1 & 1 & 2 & 1 & 3 \\
\hline 36 & 1 & 3 & 1 & 1 & 1 & 2 & 3 & 3 \\
\hline 37 & 1 & 3 & 3 & 3 & 3 & 2 & 1 & 3 \\
\hline 38 & 1 & 3 & 3 & 3 & 3 & 2 & 3 & 3 \\
\hline
\end{tabular}




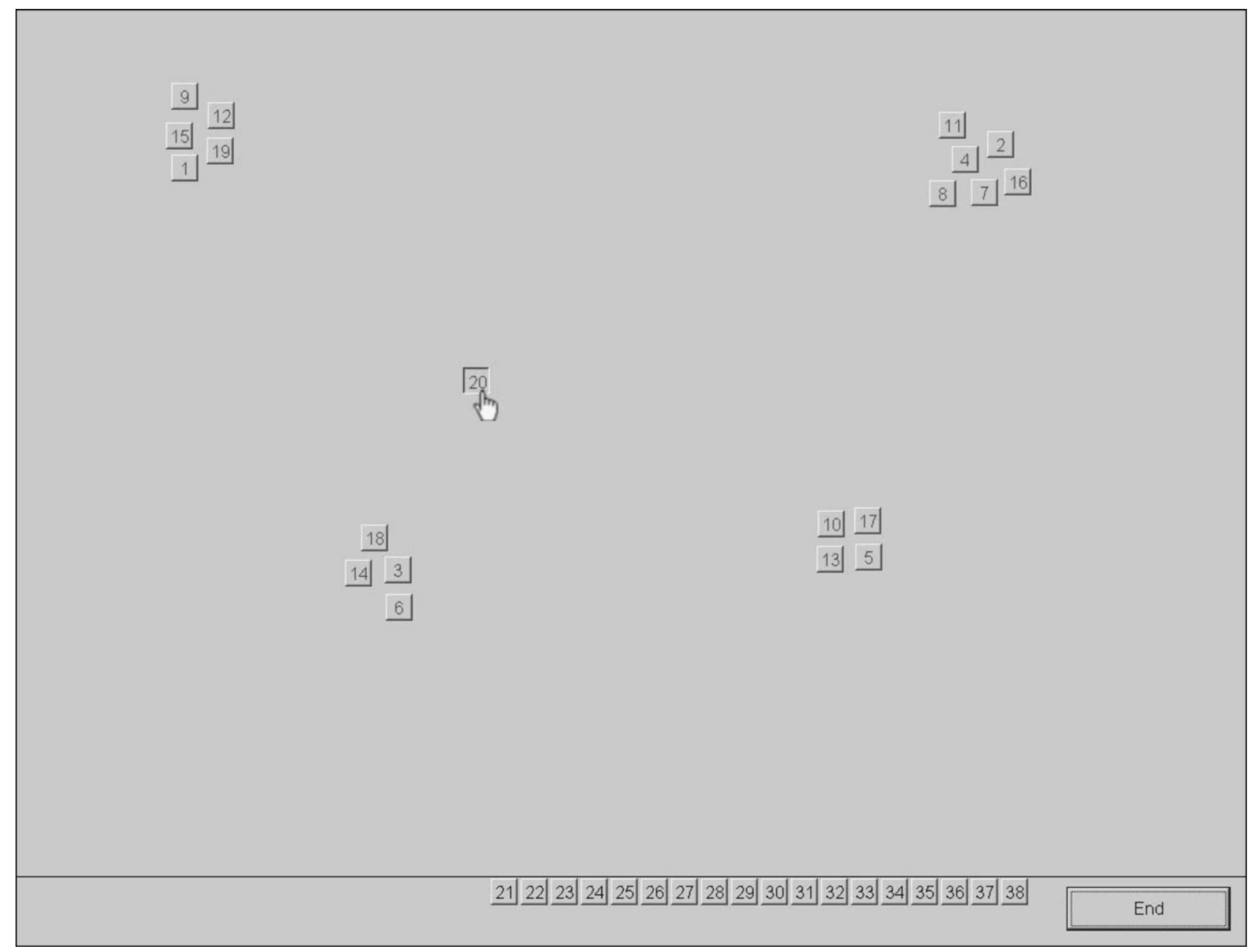

Fig. 4-Screen shot of the categorization window (running). Each button represents a sound to be assessed and can be freely moved and gathered with similar items. Sounds placed below the black line have not yet been heard. In the present case, the subject has already listened and grouped some sounds.

factors affecting the global level of the spectrum. This perceptual test procedure enabled the testing of a large stimulus set.

\subsubsection{Procedure}

During this experiment, listeners had to assess 38 sounds and to group them into equivalence classes, the equivalence relation being the perceived similarity. As shown in Fig. 4, all the 38 sounds were presented on the test window at the same time. Each button represented a sound and could be freely moved on the screen where the listeners had to group them into clusters. Sound numbers were randomly arranged so that the number attributed to each button in the test window had no link with the corresponding sound in the experiment table. The number of categories was not prescribed and could hence vary between one and thirty-eight. Instructions were orally transmitted to listeners before the beginning of the test. Subjects could listen to each stimulus as many times as they wanted. This procedure was adapted from similarity or pleasantness assessment procedures where the listener was supposed to be always able to identify the sound source. ${ }^{19}$ In our case, the listeners had no information about the stimuli and were not asked to identify their sources. Nevertheless, it was expected that this experiment would enable the identification of the latent equivalence classes within the stimulus range. The test duration varied from 18 to $35 \mathrm{~min}$ and was typically $27 \mathrm{~min}$.

\subsubsection{Results}

Each listener created his specific partition of the stimulus set. The distribution of classes among these answers is shown in Fig. 5. Each partition could be represented by a membership matrix $[a]$, where:

$a(i, j)=\left\{\begin{array}{cc}1 & \text { if sounds } i \text { and } j \text { are in the same class } \\ 0 & \text { otherwise }\end{array}\right.$ 


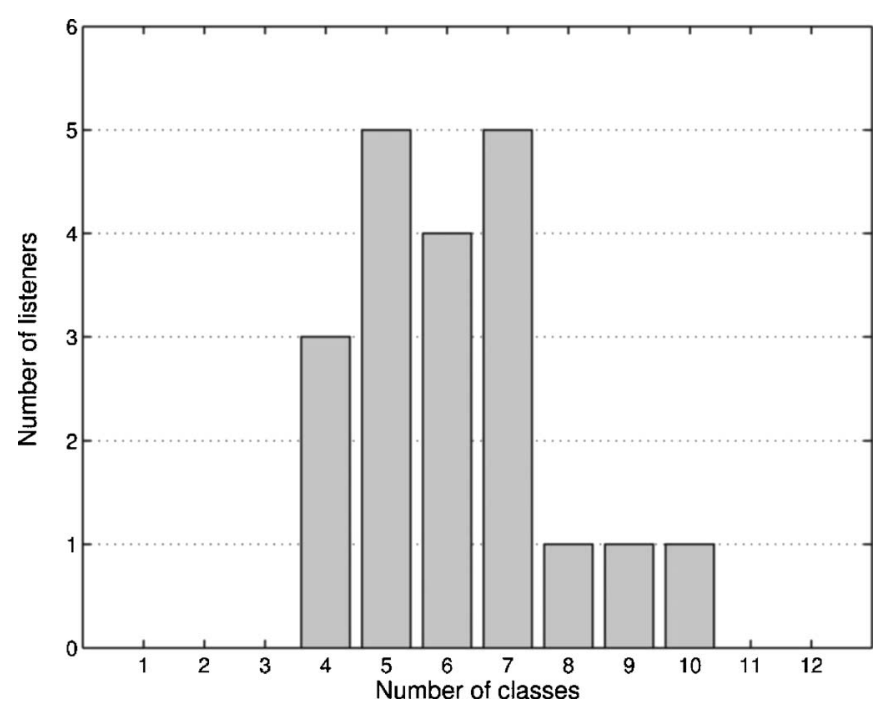

Fig. 5-Distribution of the number of classes among the 20 individual partitions.

The sum of the individual membership matrices allowed the derivation of an incidence matrix $[I]$ that could be transformed into a mean dissimilarity matrix $[D]$ :

$$
[D]=1-\frac{[I]}{n}=1-\frac{\sum_{l=1}^{n}\left[a_{l}\right]}{n}
$$

where $\left[a_{l}\right]$ is the membership matrix for listener $l, n$ being the number of participants. Using mean linkage method, this distance matrix gave the agglomeration tree (dendrogram) shown in Fig. 6. Mean partitions of the stimulus range could be obtained by cutting this tree at various agglomeration levels; the optimal partition was selected so as to match the individual ones as well as possible. The Rand index ${ }^{20}$ is an estimator of the concordance between two partitions. Hubert and Arabie $^{21}$ developed a corrected version of that index, enabling the compensation of the fact that partition correspondence could be due to chance. The corrected Rand index was computed to estimate the concordance between each mean partition (resulting from the dendrogram and containing from 1 to 38 classes) and the 20 individual partitions. As shown in Fig. 7, the best mean concordance appeared when partitioning the stimulus set into seven classes according to the agglomeration tree. The best cutting level of the dendrogram is indicated by the dashed line in Fig. 6 . The resulting partition was the one fitting the listeners' answers in the best way. It could be noted that the sounds belonging to the first class $([1 ; 12 ; 28 ; 6 ; 19 ; 8 ; 23 ; 13 ; 17]$ at the bottom of the tree) corresponded to the thinnest configuration of the plate. Such a simple physical description could not be found for the other classes.

\section{AUDITORY CUES FOR STIMULUS DIFFERENTIATION}

Differences within the synthesized sounds were perceived because of simulated mechanical variability. For each of the two experiments, analyses were performed to determine which acoustic parameters enabled the listeners to differentiate sounds.

\subsection{Linear Regression of Dissimilarity Scores}

For the responses to the first experiment (dissimilarity evaluation), a forward linear regression was used to describe the dissimilarity scores. The inputs were

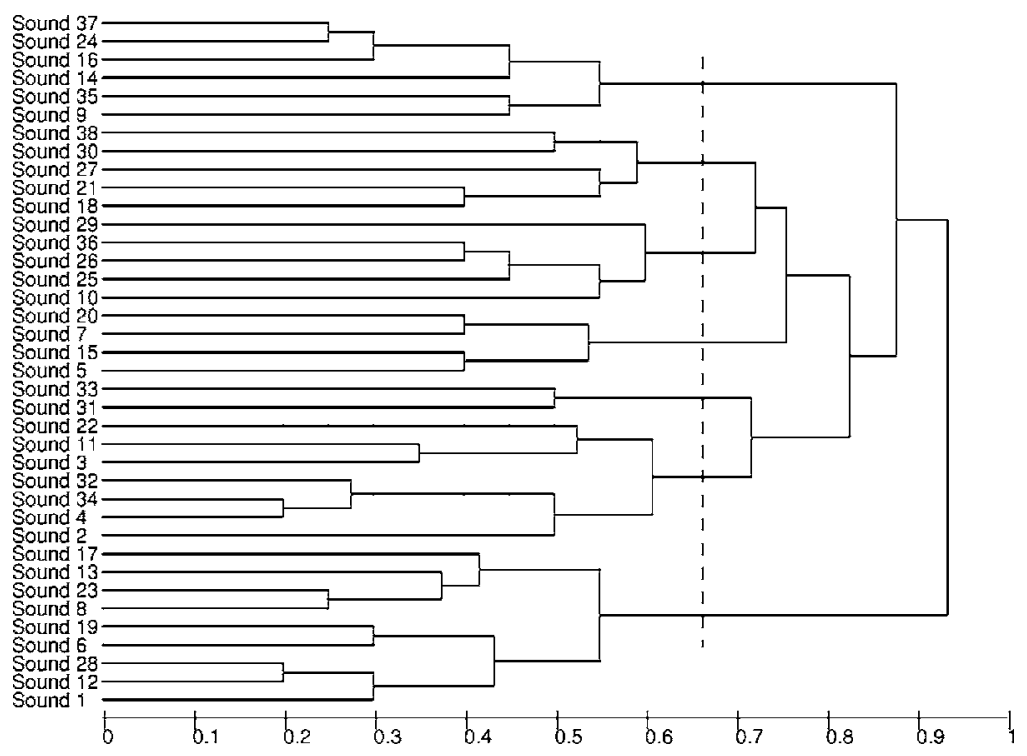

Fig. 6-Mean agglomeration tree of the stimulus set, obtained using average linkage method. The dashed line shows the optimal cutting level as indicated by the corrected Rand index. 


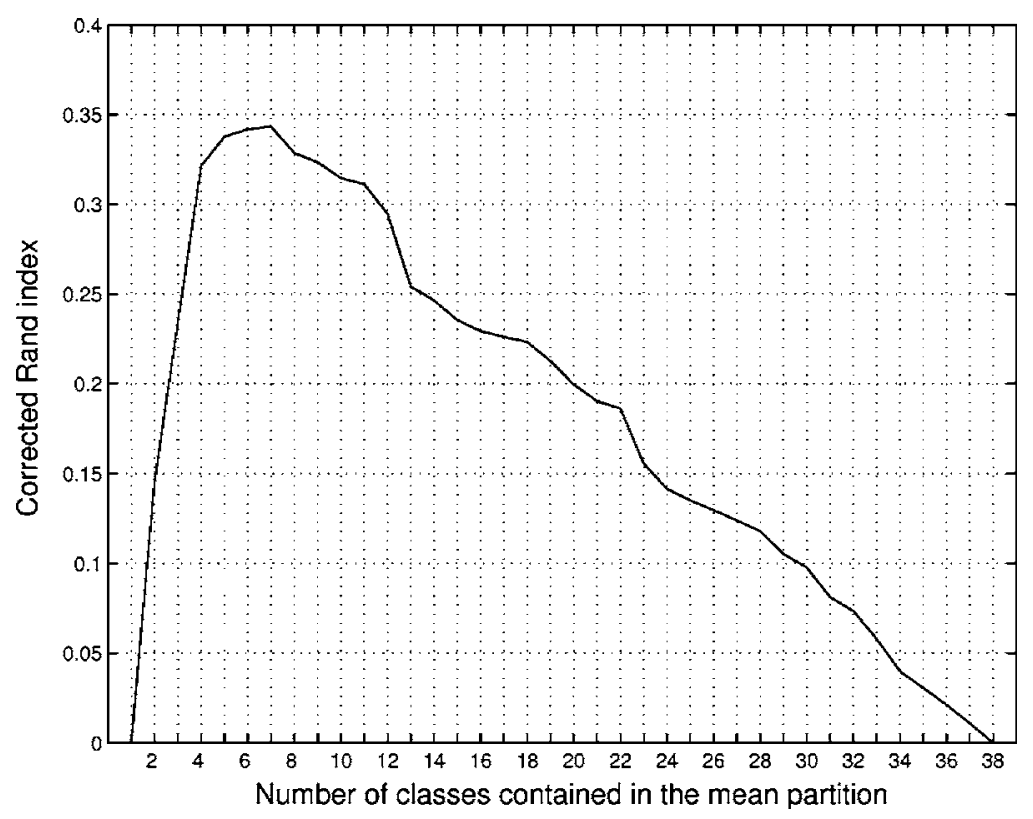

Fig. 7-Corrected Rand index, computed and averaged between each mean partition (containing 1 to 38 classes) and the 20 individual ones.

various sound quality metrics (SPL, loudness, sharpness, fluctuation strength, roughness, tonality, spectral center of gravity) computed with $01 \mathrm{~dB}$ dBSonic software (Version 4.13). A two-metrics regression model for dissimilarity $\left(R_{a j}^{2}=0.90, \mathrm{~F}(2,21)=107^{* * *}\right.$, $p<.001)$ was found. Its inputs were ISO $532 \mathrm{~B}^{22}$ loudness ( $N$, expressed in sone) and Aures ${ }^{23}$ roughness ( $R$, expressed in asper) relatively to these parameters for the reference sound:

$$
\begin{aligned}
\text { Dissimilarity score }= & 1.345 \times \frac{N}{N_{0}}+1.065 \times \frac{R}{R_{0}} \\
& -2.394
\end{aligned}
$$

where $N_{0}$ and $R_{0}$ are respectively the loudness and roughness of the reference sound. The relation between the dissimilarity scores computed using the regression model indicated in Eqn. (6) and measured ones are shown in Fig. 8. Sounds could then be aurally differentiated by loudness and roughness ratios. These parameters enabled the perception of the sound variability induced by structural uncertainty. The most important parameter appeared to be loudness (its contribution to the model described by Eqn. (6) being $83 \%$ ). But roughness (which is related to sound timbre) significantly improved the model (the roughness contribution being $7 \%$ ).

\subsection{Multidimensional Scaling of the Distance Matrix}

The perceptual space of similarity for the categorization task could be determined using a multidimen- sional analysis technique on the distance matrix resulting from the individual partitions. Multidimensional scaling (MDSCAL ${ }^{24}$ ) of the reconstituted distance matrix $[D]$ enabled the axes of the perceptual space to be found. A 3-dimensional perceptual space, shown in Fig. 9, resulted from this analysis. The first axis was strongly related to the spectral repartition of sounds and could be described $\left(R^{2}=0.84\right)$ using partial loudness in a specific Bark range:

$$
\text { Dimension } 1=\frac{\int_{2}^{4 \text { Bark }} N^{\prime}(z) \cdot d z}{N}
$$

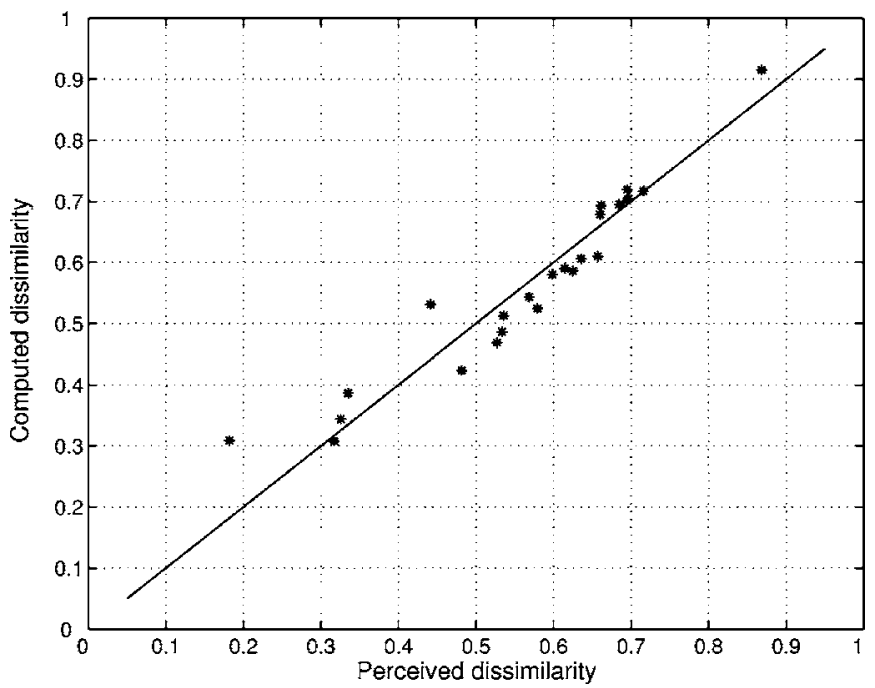

Fig. 8-Relation between the perceived and computed (using the linear regression model) dissimilarities. 


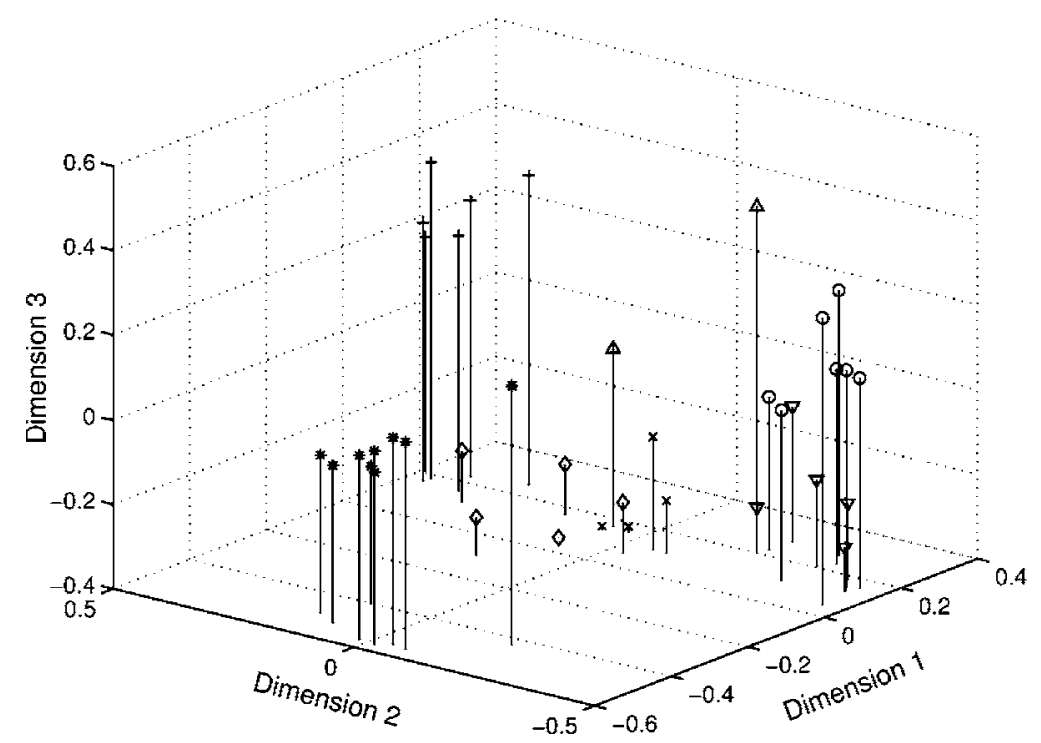

Fig. 9-Distribution of the 38 sound items into a 3-dimensional perceptual space: (*) for class 1, (०) for class $2,(\times)$ for class $3,(+)$ for class $4,(\nabla)$ for class $5,(\diamond)$ for class 6 and $(\triangle)$ for class 7 .

Depending on the value of this parameter, sounds were either categorized into the first class (according to Fig. 6) or in the six other ones. A $t$-test confirmed that the difference in the mean value of this parameter for the two distinct groups (class 1 vs. classes 2 to 7 ) was statistically significant $\left(t=-13.187^{* * *}, p<.001\right)$. The first class was related to the plate thickness, the same held for dimension 1 . The second and third dimensions were still respectively related to loudness $\left(R^{2}=0.85\right)$ and roughness $\left(R^{2}=0.61\right)$, confirming the model of Eqn. (6) obtained from the first experiment. The first and third dimensions were independent from the sound level, pitch and duration. Thus they belonged to the sound timbre. Again, differences in loudness and timbre enabled to perceive the sound variability induced by structural uncertainty.

\section{COMPARISON OF THE TWO TESTS}

These two experiments showed that structural uncertainty generated perceptible differences between various synthesis configurations. In both cases, loudness and timbre differences enabled the perception of that variability. But in the second experiment, one additional differentiation parameter, defining a separate class, appeared. The sound feature represented by this axis of the perceptual space and described by Eqn. (7) was not used by the listeners during the dissimilarity evaluation. Since this axis was related to the plate thickness, the influence of this uncertainty parameter for this experiment should then be revalued in comparison to its contribution to the first listening test. During the first experiment all sounds were compared to a reference one. All answers were conditioned by this reference, which is known as an "anchor effect".
Results thus obtained could not give as much information as the whole distance matrix obtained in the second experiment. Nevertheless, the two differentiation parameters corresponded to two axes of the perceptual space resulting from the multidimensional scaling of categorization data. This indicated that even though one of the axes was not salient for this task the acoustical parameters employed for sound differentiation were the same in the two experiments.

\section{CONCLUSION}

These listening tests allowed the quantification of the influence of structural uncertainties on sound perception, as well as the acoustical parameters used for sound differentiation. The first experiment enabled the quantification of the contribution of various uncertainty parameters to the dissimilarity perceived in comparison to the nominal sound quality. The auditory parameters used to differentiate sounds during this task were part of the perceptual space of similarity resulting from the categorization experiment. The second experiment made it possible to identify natural equivalence classes within the stimulus set, representing differences in sound perception.

This study enabled the uncertainty parameters to be pointed out that had a negligible effect on sound perception, and also the sensitive parameters affecting the acoustical parameters (loudness and timbre) used by listeners for sound differentiation. In both experiments, the most influential mechanical parameters were the force spectrum level and the plate thickness. They induced sound differences that were perceived in the loudness and timbre. 
Concerning a real industrial product, these perceptual assessment procedures could be useful in the determination of the mechanical parameters that should be controlled in order to preserve sound quality. However, the application of fractional factorial designs to industrial objects could turn out not to be as simple as it was in the first experiment because of the difficulty of controlling real parameters.

\section{REFERENCES}

1. M. S. Kompella and R. J. Bernhard, "Measurement of Statistical Variation of Structural-Acoustical Characteristics of Automotive Vehicles," SAE Paper 932172 (1993).

2. R. J. Bernhard, "The Limits of Predictability due to Manufacturing and Environmentally Induced Uncertainty," Proc. INTER-NOISE 96, pp. 2867-2872 (1996).

3. M. S. Kompella and R. J. Bernhard, "Variation of StructuralAcoustical Characteristics of Automotive Vehicles," Noise Control Eng. J. 44(2), 93-99 (1996).

4. B. Gärdhagen and J. Plunt, "Variation of Vehicle NVH Properties due to Component Eigenfrequency Shifting. Basic Limits of Predictability," SAE Paper 951302 (1995).

5. E. Rébillard and J. L. Guyader, "Calculation of the Radiated Sound From Coupled Plates," Acta. Acust. Acust. 86(2), 303$312(2000)$

6. M. Ouisse and J. L. Guyader, "Vibration Sensitive Behavior of a Connecting Angle: Case of Coupled Beams and Plates," $J$. Sound Vib. 267(4), 809-850 (2003).

7. S. McAdams, A. Chaigne, and V. Roussarie, "The Psychomechanics of Simulated Sound Sources: Material Properties of Impacted Bars," J. Acoust. Soc. Am. 115(3), 1306-1320 (2004).

8. J. Faure and C. Marquis-Favre, "Perceptual Asssessement of Structural Parameters Influence for a Radiating Plate," Acta. Acust. Acust. 91(1), 77-90 (2005).
9. J. Blauert and U. Jekosch, "Sound Quality Evaluation: A Multilayered Problem," Acta. Acust. Acust. 83(5), 747-753 (1997).

10. C. Lesueur, Rayonnement Acoustique des Structures. Vibroacoustique, Interactions Fluide-structure, Eyrolles, Paris (1988).

11. J. L. Guyader, Vibrations des Milieux Continus, Hermes Science, Paris, (2002).

12. C. Boulenger and C. Pachaud, Surveillance des Machines par Analyse des Vibrations: Du Dépistage au Diagnostic, AFNOR, Paris (1995).

13. Centre Technique des Industries Mécaniques, Matériaux Pour l'isolation Acoustique des Machines et des Véhicules, CETIM, Senlis (1995).

14. Agence française de normalisation, Produits sidérurgiques: Dimensions et tolérances, AFNOR, Paris, (1995).

15. V. Koehl and E. Parizet, "Influence of Structural Variability Upon Sound Perception: Usefulness of Fractional Factorial Designs," Appl. Acoust. 67(3), 249-270 (2006).

16. J. Alexis, Pratique Industrielle des Plans d'expérience, AFNOR, Paris, (1995).

17. G. Taguchi and S. Konishi, Taguchi Methods. Orthogonal Arrays and Linear Graphs. Tools for Quality Engineering, American Supplier Institute Press, Dearborn MI, (1987).

18. E. Parizet, N. Hamzaoui, and G. Sabatié, "Comparison of Listening Test Methods: A Case Study," Acta. Acust. Acust. 91(2), 356-364 (2005).

19. F. Guyot, M. Castellengo, and B. Fabre, "Étude de la Catégorisation d'un Corpus de Bruits Domestiques," Chap. 2 in Catégorisation et cognition: De la perception au discours, edited by D. Dubois, Kimé, Paris (1997).

20. W. M. Rand, "Objective Criteria for the Evaluation of Clustering Methods," J. Am. Stat. Assoc. 66, 846-850 (1971).

21. L. Hubert and P. Arabie, "Comparing Partitions," J. Classif. 2, 193-218 (1985).

22. E. Zwicker and H. Fastl, Psychoacoustics: Facts and Models, Berlin, Springer Verlag, (1999).

23. W. Aures, "Ein Berechnungsverfahren der Rauhigkeit," Acustica 58(5), 268-281 (1985).

24. W. S. Torgerson, 'Multidimensional Scaling: I. Theory and Method," Psychometrika 17(4), 401-419 (1952). 